\title{
von Willebrand disease and aging: an evolving phenotype.
}

Citation for published version (APA):

Sanders, YV., Giezenaar, M. A., Laros-van Gorkom, BAP., Meijer, K., van der Bom, JG., Cnossen, MH., Nijziel, MR., Ypma, PF., Fijnvandraat, K., Eikenboom, J., Mauser-Bunschoten, EP., \& Leebeek, FWG. (2014). von Willebrand disease and aging: an evolving phenotype. Journal of Thrombosis and Haemostasis, 12(7), 1066-75. https://doi.org/10.1111/jth.12586

Document status and date:

Published: 01/01/2014

DOI:

10.1111/jth.12586

Document Version:

Publisher's PDF, also known as Version of record

Document license:

Taverne

Please check the document version of this publication:

- A submitted manuscript is the version of the article upon submission and before peer-review. There can be important differences between the submitted version and the official published version of record.

People interested in the research are advised to contact the author for the final version of the publication, or visit the DOI to the publisher's website.

- The final author version and the galley proof are versions of the publication after peer review.

- The final published version features the final layout of the paper including the volume, issue and page numbers.

Link to publication

\footnotetext{
General rights rights.

- You may freely distribute the URL identifying the publication in the public portal. please follow below link for the End User Agreement:

www.umlib.nl/taverne-license

Take down policy

If you believe that this document breaches copyright please contact us at:

repository@maastrichtuniversity.nl

providing details and we will investigate your claim.
}

Copyright and moral rights for the publications made accessible in the public portal are retained by the authors and/or other copyright owners and it is a condition of accessing publications that users recognise and abide by the legal requirements associated with these

- Users may download and print one copy of any publication from the public portal for the purpose of private study or research.

- You may not further distribute the material or use it for any profit-making activity or commercial gain

If the publication is distributed under the terms of Article $25 \mathrm{fa}$ of the Dutch Copyright Act, indicated by the "Taverne" license above, 


\title{
ORIGINAL ARTICLE
}

\section{von Willebrand disease and aging: an evolving phenotype}

\author{
Y. V. SANDERS, * M. A. GIEZENAAR, *B. A. P. LAROS-VAN GORKOM, $†$ K. MEIJER, \\ J. G. VAN DER BOM, § M. H. CNOSSEN, ${ }^{*} M$. R. NIJZIEL, ††P. F. YPMA, H† K. FIJNVANDRAAT, § \\ J. EIKENBOOM, ฯ E. P. MAUSER-BUNSCHOTEN, *** and F. W. G. LEEBEEK, * FOR THE WIN STUDY \\ GROUP ${ }^{1}$ \\ *Department of Hematology, Erasmus University Medical Center, Rotterdam; †Department of Hematology, Radboud University Medical \\ Center, Nijmegen; †Department of Hematology, University of Groningen, University Medical Center Groningen, Groningen; §Department of \\ Clinical Epidemiology, Leiden University Medical Center; qJon J van Rood Center for Clinical Transfusion Medicine, Sanquin Research, \\ Leiden; **Department of Pediatric Hematology, Erasmus University Medical Center-Sophia Children's Hospital, Rotterdam; ††Department of \\ Internal Medicine, Máxima Medical Center, Eindhoven; $\$$ † Department of Hematology, HagaZiekenhuis, The Hague; §§Department of \\ Pediatric Hematology, Emma Children's Hospital, Academic Medical Center, Amsterdam; $\mathbf{q}$ Department of Thrombosis and Hemostasis and \\ Einthoven Laboratory for Experimental Vascular Medicine, Leiden University Medical Center, Leiden; and ***Van Creveldkliniek/Department \\ of Hematology, University Medical Center Utrecht, Utrecht, the Netherlands
}

To cite this article: Sanders YV, Giezenaar MA, Laros-van Gorkom BAP, Meijer K, van der Bom JG, Cnossen MH, Nijziel MR, Ypma PF, Fijnvandraat K, Eikenboom J, Mauser-Bunschoten EP, Leebeek FWG, for the WiN study group. von Willebrand disease and aging: an evolving phenotype. J Thromb Haemost 2014; 12: 1066-75.

Summary. Background: Because the number of elderly von Willebrand disease (VWD) patients is increasing, the pathophysiology of aging in VWD has become increasingly relevant. Objectives: To assess age-related changes in von Willebrand factor (VWF) and factor VIII (FVIII) levels and to compare age-related differences in bleeding phenotype between elderly VWD patients and those $<65$ years. We also studied co-morbidity in elderly patients. Patients/ Methods: We included VWD patients with VWF levels $\leq 30 \mathrm{U} \mathrm{dL}^{-1}$ in the nationwide cross-sectional 'Willebrand in the Netherlands' (WiN-) study. Patients reported bleeding episodes and treatment of VWD in the year preceding inclusion and during life. This was compared between VWD patients older $(n=71)$ and younger $(16-$ 64 years, $n=593$ ) than 65 years. In elderly patients, agerelated changes in VWF and FVIII levels were studied longitudinally by including all historically measured levels. All medical records were examined for co-morbidity. Results: In elderly type 1 patients, a decade age increase was associated with a $3.5 \mathrm{U} \mathrm{dL}^{-1}(95 \% \mathrm{CI},-0.6$ to 7.6$)$ VWF:Ag increase and $7.1 \mathrm{U} \mathrm{dL}^{-1}(95 \% \mathrm{CI}, 0.7$ to 13.4$)$

Correspondence: Frank W. G. Leebeek, Department of Hematology, Erasmus University Medical Center, PO Box 2040, 3000 CA Rotterdam, the Netherlands.

Tel.: +31 107031672 ; fax: +31 107035814 .

E-mail: f.leebeek@erasmusmc.nl

${ }^{1}$ See Appendix for full list of Contributors.

Received 18 December 2013

Manuscript handled by: P. de Moerloose

Final decision: P. de Moerloose, 15 April 2014.
FVIII:C increase. This increase was not observed in elderly type 2 patients. Elderly type 2 patients reported significantly more bleeding symptoms in the year preceding inclusion than younger patients $(16 / 27,59 \%$ vs. $87 /$ $221,39 \% ; P=0.048)$, which was not observed in type 1 VWD. Conclusions: von Willebrand factor parameters and bleeding phenotype evolve with increasing age in VWD. VWF and FVIII levels increase with age in type 1 patients with no mitigation in bleeding phenotype. In type 2 patients VWF parameters do not increase with age and in these patients aging is accompanied by increased bleeding.

Keywords: aging; factor VIII; hemorrhage; von Willebrand disease; von Willebrand factor.

\section{Introduction}

von Willebrand disease (VWD) is the commonest inherited bleeding disorder, and is caused by reduced levels or reduced function of von Willebrand factor (VWF) [1]. VWF mediates the adhesion and aggregation of platelets at sites of vascular injury, and serves as a carrier of factor VIII (FVIII) [2]. Patients with VWD suffer from bleeding episodes of which the frequency and severity are associated with the type of VWD and the remaining level of functioning VWF [3-5]. Whereas type 1 VWD is characterized by partially reduced VWF levels and type 3 by complete absence of VWF in plasma, type 2 VWD patients have abnormal variants of VWF [6].

With increasing age, VWD patients may undergo changes with regard to VWF levels, FVIII levels, bleeding 
symptoms and health status. As the number of elderly VWD patients is increasing, the pathophysiology of aging in VWD has become increasingly relevant [7].

Because plasma concentrations of VWF and FVIII have been shown to increase with age in healthy individuals [8-10], they are also likely to increase in aging VWD patients. Hypothetically, one would expect these higher levels to mitigate the bleeding phenotype, which may be associated with reductions in VWD concentrate treatment dose and intensity. When VWF and FVIII levels increase, they might also cross the threshold of current diagnostic criteria for VWD in some elderly patients with mild type 1 VWD [6]. However, these increased levels may still be too low for adequate hemostasis.

In elderly VWD patients, bleeding frequency and severity are influenced by various factors. For example, the risk of bleeding may be reduced by a more sedentary lifestyle with fewer physical challenges. Similarly, common co-morbidities in elderly patients, such as malignancies, may increase the risk of bleeding, as a result of disease or surgical procedures [11]. It has also been suggested that, due to degenerative intestinal changes and angiodysplasia, elderly VWD patients suffer from more frequent gastrointestinal bleeding than younger patients [7].

In this nationwide cross-sectional study, we studied age-related changes in VWF and FVIII levels and compared the differences in bleeding phenotype between elderly VWD patients and patients younger than 65 years. We also studied specific age-related co-morbidity in elderly VWD patients.

\section{Patients and methods}

\section{Participants}

We performed a nationwide cross-sectional study among von Willebrand disease (VWD) patients in the Netherlands: the 'Willebrand in the Netherlands' (WiN-) study $[3,12,13]$. We included patients diagnosed with type 1 , type 2 and type 3 VWD who had a hemorrhagic diathesis or a family history of VWD and had historically lowest VWF levels $\leq 30 \mathrm{U} \mathrm{dL}^{-1}$ (VWF:Ag and/or VWF:RCo) and/or FVIII levels (FVIII:C) $\leq 40 \mathrm{U} \mathrm{dL}^{-1}$ (for type $2 \mathrm{~N} \mathrm{VWD).}$ Patients were excluded if they were known to have hemophilia A or other hemostatic disorders resulting in hemorrhagic diathesis. Between October 2007 and October 2009, 804 individuals were included. In total, 664 patients aged $\geq 16$ years participated, with $71(11 \%) \geq 65$ years. The medical ethical committees at all participating centers approved this study, and all participants gave informed consent. This has been described in detail previously [3].

\section{Assessment methods in the study}

All patients completed an extensive questionnaire on co-morbidity, hospitalization, bleeding episodes and treatment of VWD in the year preceding inclusion $[3,14,15]$. First a pilot study using the think-aloud method' was conducted in which respondents completed the questionnaire in the presence of the investigator and then adjustments were made accordingly [16]. All patients were asked to report the bleeding episodes and treatment of VWD in the year preceding inclusion. We also collected information about the severest lifetime episode of 12 specific types of bleedings by administration of the Tosetto Bleeding Questionnaire [17]. We did not score for a bleeding symptom if patients received prophylactic desmopressin or prophylactic replacement therapy before they underwent surgery or dental extraction, to avoid prophylaxis bias $[3,18]$. However, if bleeding after surgery or dental extraction had occurred despite prophylactic treatment, we scored for this bleeding according to the Tosetto bleeding score. Because of the limitations of the Tosetto bleeding score (cumulative score, ceiling effect and prophylaxis bias) $[3,4,18]$, we mainly focused on bleeding episodes in the year preceding inclusion in the study. In addition, we reviewed all elderly patients' medical records and studied their co-morbidities and medication use.

In most elderly patients $(n=66)$, VWF parameters had been determined at several time-points (at least twice) in the past 30 years in their own Hemophilia Treatment Centers. To study the age-related changes in VWF and FVIII levels within elderly patients over time, all such historical VWF and FVIII levels were included. Blood samples obtained within $72 \mathrm{~h}$ after the use of desmopressin or replacement therapy and obtained during pregnancy have been excluded.

\section{Laboratory measurements in von Willebrand disease patients}

Patients' historically measured VWF parameters had been determined previously in their Hemophilia Treatment Centers. Plasma levels of VWF antigen (VWF:Ag), VWF collagen binding (VWF:CB), VWF activity (VWF:Act) and FVIII coagulation activity (FVIII:C) were also measured centrally at inclusion in the study (Erasmus University Medical Center, Rotterdam) [3]. Venous whole blood was collected in $0.105 \mathrm{~m}$ sodium citrate tubes and centrifuged twice at $2200 \times g$ for $10 \mathrm{~min}$ at room temperature and stored at $-80{ }^{\circ} \mathrm{C}$. VWF:Ag was determined with an in-house ELISA using polyclonal rabbit anti-human VWF antibodies and horseradish peroxidase (HRP) conjugated anti-human VWF antibodies (DakoCytomation, Glostrup, Denmark) for detection. VWF:CB was measured with an in-house ELISA using collagen type 1 (Sigma-Aldrich, St Louis, MO, USA) for capture and HRP-conjugated anti-human VWF antibody (DakoCytomation) for detection. A VWF:Act assay was used to assess VWF activity. This assay uses monoclonal antibodies directed against the GpIb $\alpha$ binding domain of VWF 
and thereby reflects the binding activity of VWF to GpIb $\alpha$ (HemosIL $^{\mathrm{TM}}$ von Willebrand Factor Activity; Instrumentation Laboratory BV, Breda, the Netherlands). We have previously validated the VWF:Act test $(n=122)$ and obtained a Spearman correlation coefficient of 0.942 with our previously used VWF:RCo activity test $(P<0.0001)$ [3]. FVIII:C was measured in a one-stage clotting assay (TriniCLOT, Biomerieux, Marcy l'Etoile, France) with FVIII-deficient plasma (Biopool, Umea, Sweden) and reference plasma (Precision biologic, Kordia, Leiden, the Netherlands). Details on the blood sampling procedure and laboratory measurements at inclusion in the study have been described in more detail by de Wee et al. [3].

\section{Definitions}

Elderly patients were defined as VWD patients $\geq 65$ years of age at time of inclusion based on WHO criteria [19] and younger patients as VWD patients 16-64 years of age at time of inclusion. The lifetime prevalence of bleeding symptoms was defined as clinically relevant bleeding symptoms that have occurred at least once during life, identified through the Tosetto Bleeding Questionnaire $[4,20]$. Co-morbidity was defined as the presence of any disease or condition other than the patient's VWD that required medical attention from a general practitioner or specialist. Part of the questionnaire concerned the clinical history of all kinds of co-morbidity, which was defined as self-reported co-morbidity. Co-morbidities were categorized using the following categories: HIV, hepatitis C, hepatitis B, overweight (BMI of 25-30), obesity (BMI>30), hypertension, hypercholesterolemia, chronic arthropathy, diabetes, renal disease, depression, respiratory disease, gastrointestinal disease, thyroid disease, neurological disease, cancer, cardiovascular disease, ocular disease, dermatological disease, urinary tract disease and other. The classification of co-morbidities is further specified in Table S1.

\section{Statistical methods}

Because data were not normally distributed, continuous variables are presented as median and $25-75 \%$ interquartile range (IQR). Descriptive statistics for categorical data are presented as frequencies and proportions $(n, \%)$. The chi-squared test or the Fisher's exact test is used to compare the prevalence of bleedings in the past and in the year preceding inclusion, and the prevalence of selfreported co-morbidity between patients younger and older than 65 years. The Mann-Whitney $U$-test is used to test the differences in VWF:Ag, VWF:Act and FVIII:C between patients younger and older than 65 years. First, in elderly patients $(n=66)$ we used linear mixed models to model the association between age and all historically measured VWF:Ag, VWF:Act and FVIII:C levels.
Secondly, linear regression analyses were used to determine the association between age and centrally measured VWF:Ag, VWF:Act and FVIII:C levels in all type 1 and type 2 patients $\geq 16$ years from the WiN study $(n=664)$. Statistical analyses were performed with SPSS for Windows, version 20.0 (SPSS Inc, Chicago, IL, USA). A $P$-value $<0.05$ was considered statistically significant.

\section{Results}

In total, 71 VWD patients aged 65-85 years were included in the WiN study and 593 VWD patients aged 16-64 years (Table 1). Over half of the elderly patients were female $(n=47,66 \%)$, had type 1 VWD $(n=43$, $61 \%)$ and blood group $\mathrm{O}(n=37,52 \%)$.

\section{Age-related changes in VWF and FVIII levels}

Centrally measured VWF:Ag levels at inclusion were significantly higher in elderly patients than in those younger than 65 years: the VWF:Ag level in elderly patients was $38 \mathrm{IU} \mathrm{dL}^{-1}$ [median; IQR 24-53] and in patients $<65$ years $30 \mathrm{IU} \mathrm{dL}^{-1} \quad[19-46] \quad(P=0.033)$. Elderly patients also had significantly higher levels of FVIII:C $\left(62 \mathrm{IU} \mathrm{dL}^{-1}\right.$ [47-85]) than patients $<65$ years (52 IU $\left.\mathrm{dL}^{-1}[34-75]\right)(P=0.011)($ Table 1$)$.

In a subset of 66 elderly patients for whom historically measured VWF and FVIII levels were available over time, we studied the association between age and VWF parameters using linear mixed models. VWF:Ag, VWF:Act and FVIII:C levels increase with age in type 1 patients $(n=40)$ : a decade age increase was associated with a $3.5 \mathrm{U} \mathrm{dL}^{-1}$ (95\% CI, -0.6 to 7.6) VWF:Ag increase, $9.5 \mathrm{U} \mathrm{dL}^{-1}(95 \% \mathrm{CI}, 3.7$ to 15.3$)$ VWF:Act increase and $7.1 \mathrm{U} \mathrm{dL}^{-1}$ (95\% CI, 0.7 to 13.4) FVIII:C increase. In type 2 patients $(n=26)$, this age-related increase in VWF and FVIII levels was not observed: VWF:Ag, $-1.6 \mathrm{U}$ $\mathrm{dL}^{-1}(95 \% \mathrm{CI},-10.3$ to 7.2$)$; VWF:Act, $0.5 \mathrm{U} \mathrm{dL}^{-1}$ (95\% CI, -2.8 to 3.7); FVIII:C, $-0.1 \mathrm{U} \mathrm{dL}^{-1}$ (95\% CI, -15.0 to 14.9$)$.

In Fig. 1 centrally measured VWF:Ag, VWF:Act and FVIII:C levels for all individual type 1 and type 2 patients $\geq 16$ years are depicted. In type 1 VWD, VWF: $\mathrm{Ag}$ increases by $2.7 \mathrm{IU} \mathrm{dL}^{-1}$ (95\% CI, 1.1 to 4.2$)$ per decade, VWF:Act by $4.1 \mathrm{IU} \mathrm{dL}^{-1}(95 \% \mathrm{CI}, 2.0$ to 6.3 ) and FVIII:C by $3.7 \mathrm{IU} \mathrm{dL}^{-1}(95 \% \mathrm{CI}, 1.6$ to 5.9$)$. In type 2 VWD, VWF:Ag increases by $2.1 \mathrm{IU} \mathrm{dL}^{-1}(95 \%$ CI, 0.7 to 3.4) per decade and FVIII:C by $2.1 \mathrm{IU} \mathrm{dL}^{-1}$ ( $95 \%$ CI, 0.2 to 4.0). VWF:Act did not increase in type 2 VWD: $1.0 \mathrm{IU} \mathrm{dL}^{-1}$ (95\% CI, -0.6 to 2.6$)$.

\section{Bleeding symptoms that required desmopressin or replacement therapy in the year preceding inclusion}

At inclusion, patients were asked to report the bleeding symptoms encountered in the preceding year. Compared 
Table 1 Baseline characteristics

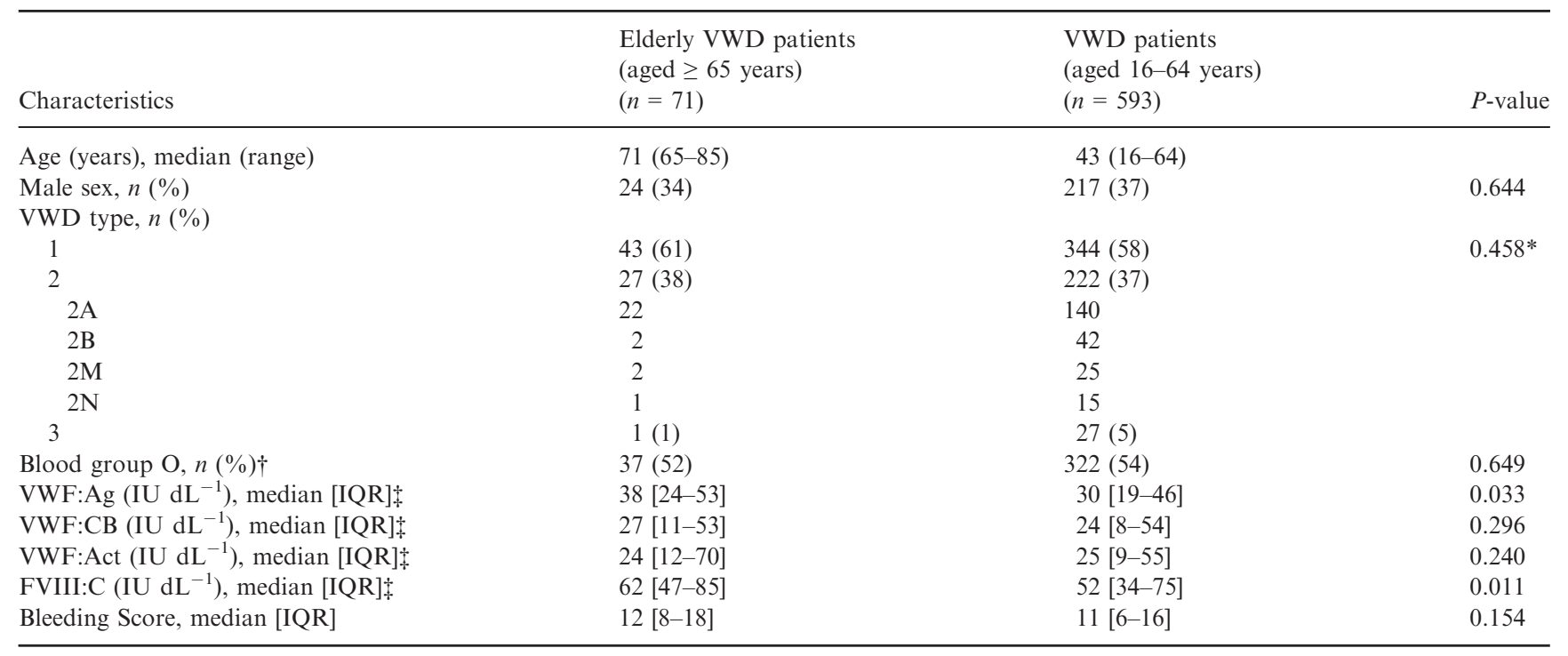

VWD, von Willebrand disease; IQR, 25-75\% interquartile range; VWF:Ag, von Willebrand factor antigen; VWF:CB, von Willebrand factor collagen binding; VWF:Act, von Willebrand factor activity; FVIII:C, factor VIII coagulation activity. ${ }^{*} P$ for trend between type 1 , type 2 and type 3. †Elderly $n=63$ and adults $n=522$, based on availability. $\$$ Elderly $n=62$ and adults $n=507$, patients without centrally measured VWF parameters, and patients who used desmopressin or clotting factor concentrate $72 \mathrm{~h}$ before blood sampling were excluded.

with the patients aged $<65$ years, more elderly patients reported a bleeding episode that required treatment in the year preceding inclusion $(30 / 71,42 \%$ vs. $182 / 593,31 \%$; $P=0.048)$, which was also observed after exclusion of the type 3 patients $(29 / 70,41 \%$ vs. $165 / 566,29 \%$; $P=0.035) \quad$ (Fig. 2A). This bleeding difference was explained by a difference among type 2 patients. Elderly type 2 patients reported significantly more bleeding that required treatment in the year preceding inclusion than those < 65 years $(16 / 27, \quad 59 \%$ vs. $87 / 222, \quad 39 \%$; $P=0.046)$, whereas there was no difference in bleeding rate between younger and older type 1 patients $(13 / 43$, $30 \%$ vs. $78 / 344,23 \% ; P=0.271$ ). In elderly patients, gastrointestinal bleeding requiring treatment had occurred in a larger proportion in the year preceding inclusion than in younger patients $(4 / 71,6 \%$ vs. $11 / 593,2 \% ; P=0.043)$ (Fig. 2B).

\section{Lifetime prevalence of bleeding symptoms}

The commonest bleeding symptoms reported by the elderly VWD population were cutaneous bleeding (52/71, $73 \%)$, bleeding after tooth extraction $(47 / 61,77 \%$ of the patients who underwent tooth extraction) and post-surgical bleeding $(46 / 64,72 \%$ of the patients who underwent surgery). Other reported bleeding symptoms were gastrointestinal bleeding $(17 / 71,24 \%)$, muscle hematoma (16/ $71,23 \%)$, hemarthrosis $(17 / 71,24 \%)$ and central nervous system bleeding (1/71, 1\%) (Fig. 3).

Compared with patients $<65$ years, a higher number of elderly patients had had gastrointestinal bleeding (17/71, $24 \%$ vs. $83 / 593,14 \% ; P=0.027)$. This was also observed after exclusion of the type 3 patients (16/70, 23\% vs. $76 /$ $566,13 \% ; P=0.034)$. In the proportion of VWD patients who underwent a surgical procedure, more elderly patients reported post-surgical bleeding than patients $<65$ years $(46 / 64,72 \%$ vs. $256 / 495,52 \% ; P=0.002)$, which was also observed after exclusion of the type 3 patients $(41 / 57,72 \%$ vs. $220 / 424,52 \% ; P=0.004)$. Bleeding from minor wounds was reported significantly less by elderly patients $(44 / 71,62 \%$ vs. 468/593, 79\%; $P=0.001)$. Also, if type 3 patients were included, elderly patients reported significantly less bleeding from minor wounds $(44 / 70, \quad 54 \%$ vs. $446 / 566, \quad 75 \% ; \quad P=0.003)$ (Fig. 3).

Elderly type 2 patients reported significantly more postsurgical bleeding $(15 / 20,75 \%$ vs. $75 / 152,49 \% ; P=0.031)$ and a trend was observed towards significantly more gastrointestinal bleeding $(9 / 27,33 \%$ vs. $41 / 222,18 \%$; $P=0.069$ ). In type $1 \mathrm{VWD}$, the lifetime prevalence of all bleeding symptoms was similar between elderly patients and those $<65$ years of age.

Bleeding score did not differ between elderly and younger patients $(12[8-18]$ vs. 11 [6-16]; $P=0.154)$ (Table 1$)$. Also for type 1 and type 2 VWD separately no difference was observed in bleeding score $(P=0.293$ and $P=0.238$, respectively).

\section{Self-reported co-morbidity in elderly patients compared with younger patients}

From 67 (67/71, 94\%) elderly patients and from 580 (580/ 593, 98\%) younger patients, self-reported co-morbidity data was available. Of those patients, more elderly patients 
Type 1 VWD and VWF:Ag

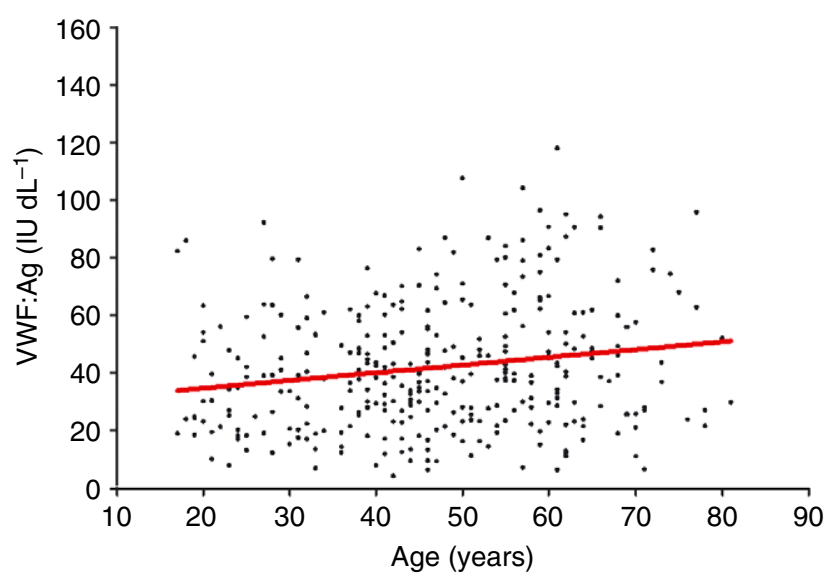

Type 1 VWD and VWF:Act

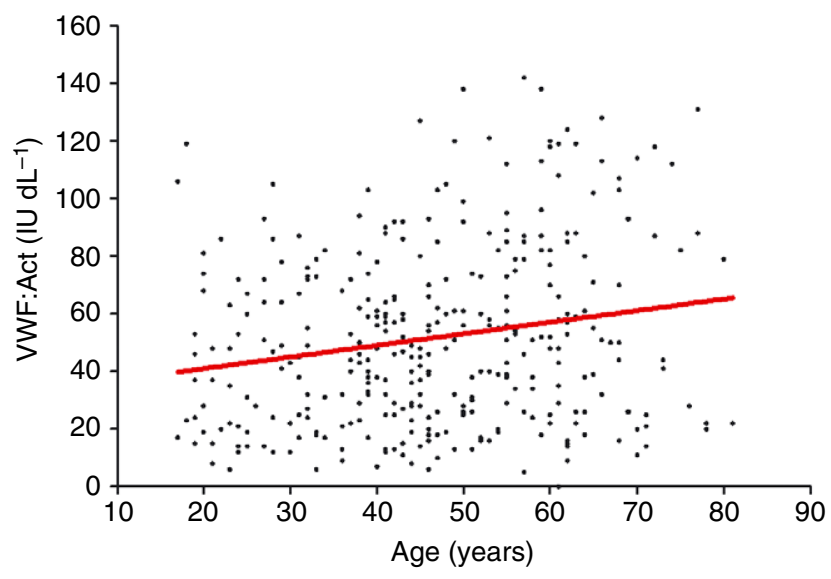

Type 1 VWD and FVIII:C

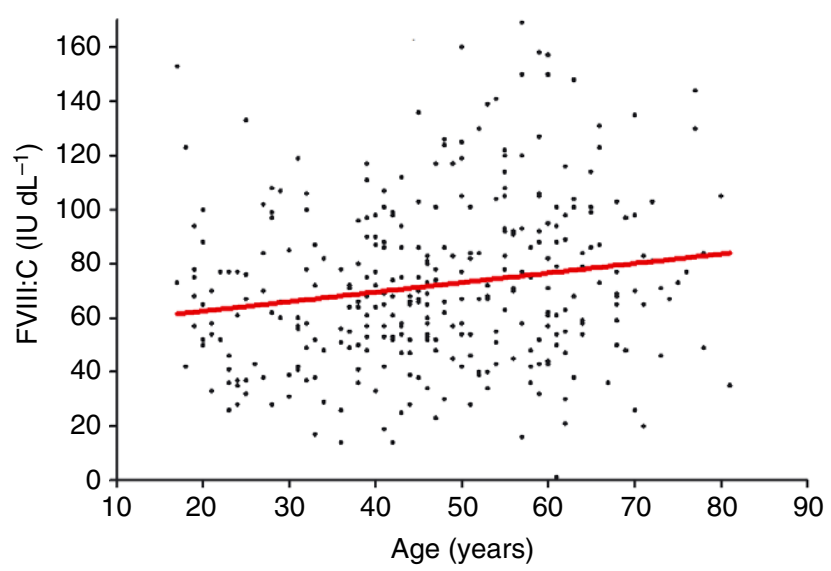

Type 2 VWD and VWF:Ag

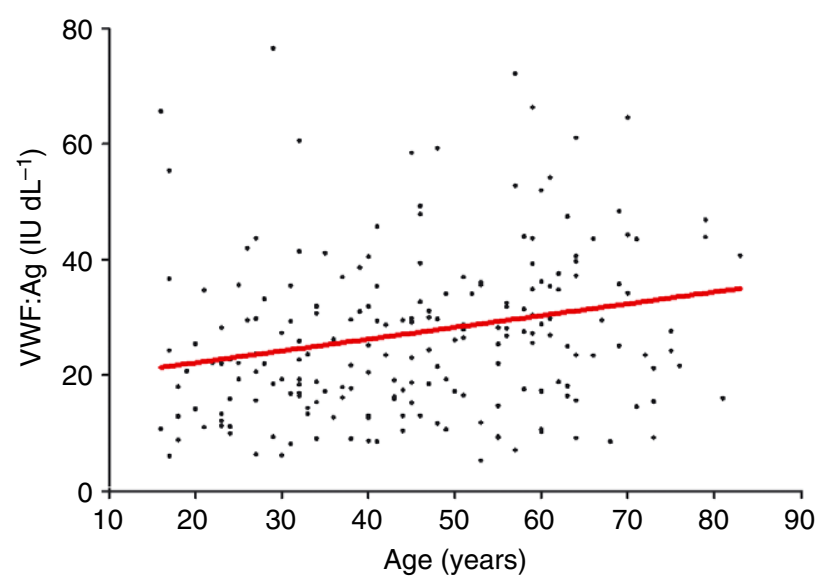

Type 2 VWD and VWF:Act

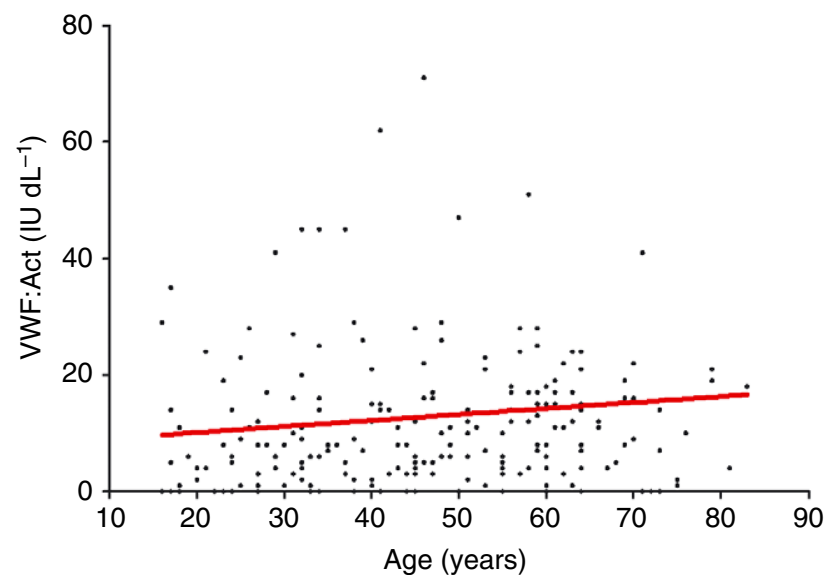

Type 2 VWD and FVIII:C

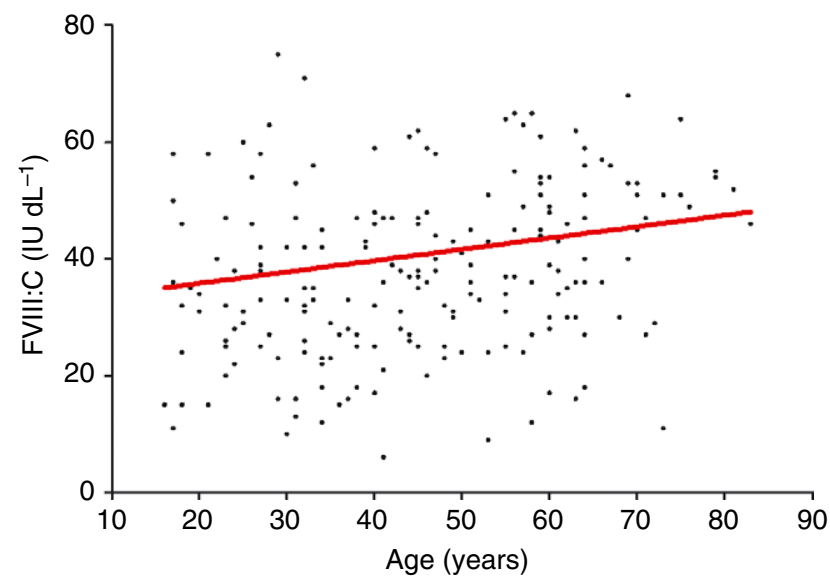

Fig. 1. Centrally measured VWF:Ag, VWF:Act and FVIII:C levels according to age in all type 1 and type 2 VWD patients aged 16-85 years at inclusion in the WiN study. Type 1 VWD $n=338$ and type 2 VWD $n=208$.

reported one or more co-morbidities than younger ones (49/67, $73 \%$ vs. $241 / 580,42 \% ; P<0.001)$. In both groups, hypertension was the most frequently self-reported co-morbidity, but in the elderly the prevalence was significantly higher $(35 / 67,52 \%$ vs. $81 / 580,14 \% ; P<0.001)$. Diabetes, cancer and cardiovascular disease were also 

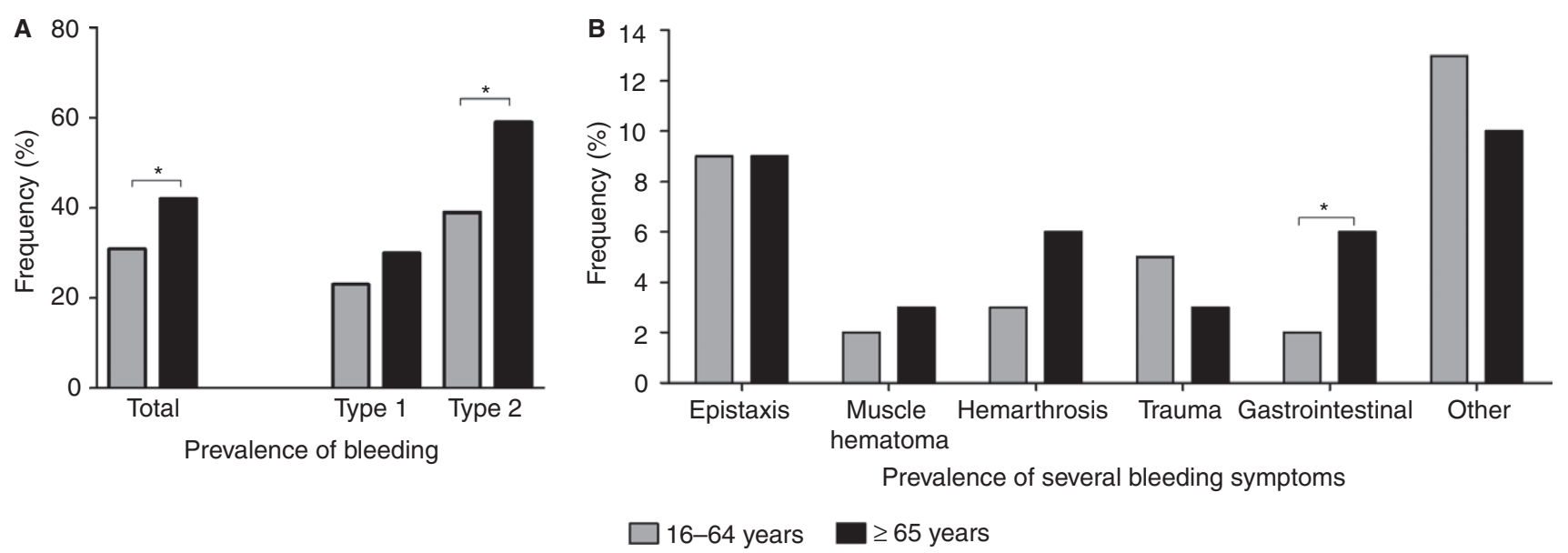

Fig. 2. (A) Prevalence of bleeding that required desmopressin or replacement therapy in the year preceding inclusion in the study. (B) Prevalence of different bleeding symptoms that required desmopressin or replacement therapy in the year preceding inclusion in the study. Other bleeding symptoms include oral cavity bleeding, post-surgical bleeding, hematuria and ocular hemorrhage. ${ }^{*} P<0.05$.

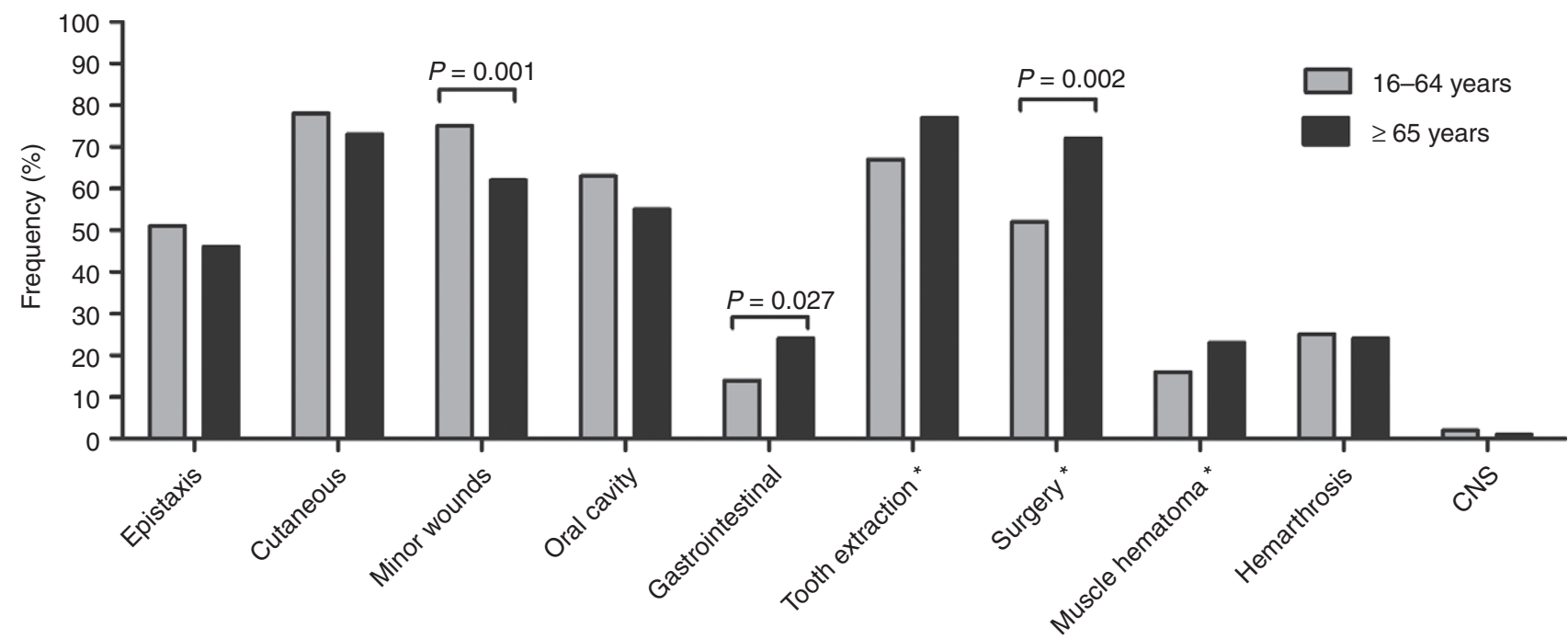

Fig. 3. Lifetime prevalence of bleeding symptoms in elderly VWD patients compared with VWD patients below 65 years of age. *Frequencies are from patients who ever underwent a tooth extraction or surgery.

more frequently self-reported by elderly patients than those $<65$ years (diabetes: $6 / 67,9 \%$ vs. $16 / 580,3 \%$; $P=0.019$; cancer: $8 / 67,12 \%$ vs. $23 / 580,4 \% ; P=0.010$; and cardiovascular disease: $17 / 67,25 \%$ vs. $31 / 580,5 \%$; $P<0.001)$. In addition, more elderly patients selfreported depression $(6 / 67,9 \%$ vs. $8 / 580,1 \% ; P=0.002)$. The prevalence of all other classified co-morbidities (Table S1) did not differ between those younger and older than 65 years of age. The above-mentioned numbers of self-reported co-morbidities were not verified in medical files.

\section{Co-morbidities in elderly VWD patients}

Co-morbidity was assessed in elderly VWD patients by checking the medical charts of all individual patients.
Nearly all elderly patients $(66 / 71,93 \%)$ suffered from comorbidities and most of them had two or more co-morbidities $(61 / 71,86 \%)$. The prevalence of co-morbidities in elderly patients is shown in Fig. 4. Hypertension was the commonest co-morbidity among elderly patients (46/71, $65 \%)$. Viral infections were not common; there were no patients infected with HIV, one $(1.4 \%)$ with chronic hepatitis B and four $(5.6 \%)$ with chronic hepatitis C. Cardiovascular disease was present in 22 elderly patients $(22 / 71$, $31 \%$ ), who reported a total of 40 different cardiovascular disorders. Cardiac arrhythmias were commonest (10/40, $25 \%$ ), followed by unstable angina pectoris $(6 / 40,15 \%)$ and heart valve disease $(6 / 40,15 \%)$. Twenty patients $(20 /$ $71,28 \%)$ suffered from chronic arthropathy, occurring in $26 \%(11 / 43)$ of type 1 and $33 \%(9 / 27)$ of type 2 patients $(P=0.485)$. Chronic arthropathy was not reported by the 


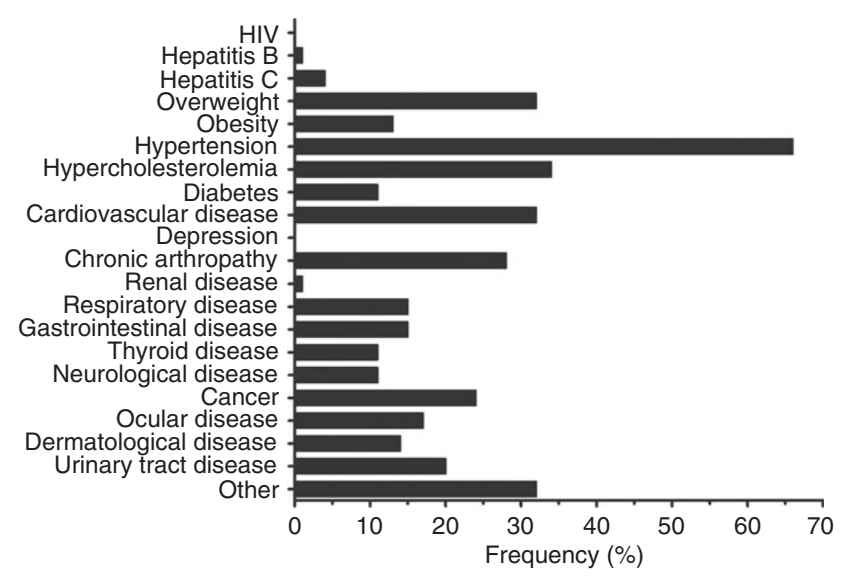

Fig. 4. Prevalence of co-morbidities in the elderly VWD patients.

type 3 patient. The joints most commonly affected were the knee $(n=5)$, hip $(n=4)$ and spine $(n=4)$.

Eleven out of 71 patients $(15 \%)$ had gastrointestinal disease. The prevalence of gastrointestinal bleeding did not differ between patients with and without gastrointestinal disease $(P=0.441)$. Seventeen elderly patients $(24 \%)$ had a history of 20 different malignancies. Skin cancer, including basal cell carcinoma, squamous cell carcinoma and melanoma, was the commonest $(7 / 20,35 \%)$, followed by colon cancer $(n=3)$, breast cancer $(n=3)$ and prostate cancer $(n=3)$. Other malignancies reported were renal cell cancer, bladder tumor and a pheochromocytoma.

\section{Hospitalizations and surgeries in the year preceding inclusion}

Thirteen elderly patients $(13 / 71,19 \%)$ had been hospitalized in the year preceding inclusion, which was similar to patients $<65$ years $(123 / 593,21 \% ; P=0.631)$. The median number of days of hospitalization was 3 (IQR $1.5-$ $4.0)$. The main reasons for hospitalization were surgery $(9 / 13,64 \%)$ and bleeding $(2 / 13,14 \%)$ (data not shown).

\section{Discussion}

This first nationwide cross-sectional study of elderly VWD patients shows that VWF:Ag, VWF:Act and FVIII:C increase with age in elderly type 1 patients, but not in elderly type 2 patients. In addition, in the year preceding inclusion, bleeding that required treatment occurred more frequently in elderly type 2 patients than in younger type 2 patients, while such a difference was not found between type 1 patients younger than 65 years of age and type 1 patients older than 65 years of age.

In healthy individuals, it is known that VWF and FVIII levels increase with age [9,10,21]. Our analyses of VWF and FVIII levels measured over time in a subset of elderly individuals showed that an increase with age also occurs in type 1 VWD patients, which is in accordance with a smaller recent study [22]. This longitudinally measured increase in VWF parameters with age within elderly patients was not found in type 2 VWD. In addition, centrally measured VWF:Act does not increase with age in type 2 VWD. Interestingly, compared with their respective $<65$ years age group, elderly type 2 patients suffered from more bleeding that required desmopressin or replacement therapy in the year preceding inclusion. Conversely, in type 1 patients, this bleeding rate was similar in elderly and younger patients. Unfortunately, we were not able to analyze difference within type 2 VWD, because of the low number of the various subtypes. However, we have previously shown that $2 \mathrm{~B}$ and $2 \mathrm{~A}$ patients had a more severe bleeding phenotype, which is in accordance with Castaman et al. [3,23]. These data suggest that the increase in VWF and FVIII levels observed in elderly type 1 patients may mitigate an age-related increase of bleeding. The increase in plasma levels is possibly physiological, as it also occurs in healthy individuals. Also, with increasing age, higher levels of VWF and FVIII may be necessary for adequate hemostasis in both healthy and VWD individuals. Tosetto et al. [4] have shown that bleeding score did not increase with age in healthy controls. At the same time, as a consequence of the increase in VWF parameters elderly patients with mild type 1 VWD may no longer meet the current diagnostic criteria for VWD [6].

The bleeding pattern in VWD observed in this study also clearly evolves with increasing age. In the year preceding inclusion in the study, more elderly patients suffered from gastrointestinal bleedings than younger patients. Also, the lifetime prevalence of gastrointestinal bleeding was higher in elderly patients than in younger patients. This has also been observed in the general elderly population [24] and could be explained by the occurrence of degenerative intestinal changes and angiodysplasia in the elderly [25]. It is known from the general population that approximately $35-45 \%$ of all patients presenting with upper gastrointestinal bleeding are over the age of 60 and that the incidence rate of lower gastrointestinal bleeding increases more than 200-fold from the third to the ninth decade of life [26,27]. Gastrointestinal bleedings are often severe and difficult to treat in VWD patients, indicating a possible benefit from prophylactic treatment in elderly patients [28,29]. The increase in bleeding in the year before inclusion may also be driven by hemarthrosis, which could be related to degenerative osteoarticular changes in the elderly patients. However, in our study, chronic arthropathy occurred in $28 \%$ of elderly VWD patients, which is much lower than the prevalence reported in elderly hemophilia patients (69\% and $95 \%$ for elderly with severe disease) [30,31], probably because hemarthrosis is less common in VWD than in hemophilia.

In VWD patients who underwent a surgical intervention, we also found that elderly patients reported more 
post-surgical bleeding than younger ones, possibly because they had undergone more major surgical procedures, such as orthopedic surgery, which is characterized by a high bleeding risk [32]. Indeed, in our cohort more orthopedic interventions were performed in elderly patients than in younger ones $(22 / 64,34 \%$ vs. 104/495, $21 \% ; P=0.019)$. In order to reduce post-surgical bleeding in elderly VWD patients, it may be necessary to adjust preoperative and/or postoperative treatment on the basis of FVIII and VWF levels. However, before conclusions can be drawn, this should be studied prospectively.

To our knowledge, this is the first report on co-morbidities in elderly VWD patients. Many elderly individuals with VWD suffer from co-morbidities, which might interact with VWF levels or VWD treatment. If co-morbidity induces a less active lifestyle, patients may suffer fewer bleedings. On the other hand, the frequency and severity of bleeding may increase if more surgical procedures or treatments with antiplatelet and anticoagulant drugs or chemotherapy are needed because of co-morbidities. In our cohort of 71 elderly patients, HIV did not occur and chronic hepatitis $\mathrm{B}$ and $\mathrm{C}$ infections were rare, but higher than in the general population, with a prevalence of $0.4 \%$ and $0.002 \%$, respectively [33,34]. This is in contrast to elderly hemophilia patients [11,35], in whom the prevalence of HIV infections ranges from $3.5 \%$ to $13 \%$, and that of hepatitis $\mathrm{C}$ infections ranges from $69 \%$ to $92 \%$ [30,36]. Although some patients may have died before inclusion, most VWD patients probably received less factor-replacement therapy than hemophilia patients, and therefore suffered fewer transfusion-transmitted viral infections [37].

In our study, a quarter of elderly VWD patients had a history of malignancies and $5 \%$ of all patients $\geq 16$ years self-reported a prevalent cancer, which is higher than the prevalence of $3.5 \%$ in the general Dutch population [38]. In VWD patients, the management of cancer remains a challenge for physicians. Diagnostic and elective procedures may require proper replacement therapy, and the fact that thrombocytopenia is a well-known side-effect of chemotherapy means that more treatment of VWD might be needed to prevent or treat a bleed [39].

Several elderly patients suffered from various cardiovascular disorders, mainly cardiac arrhythmias, angina pectoris and heart valve disease. We have recently shown that VWD patients have a lower prevalence of coronary heart disease, acute myocardial infarction and ischemic stroke, a higher prevalence of hypertension and a similar prevalence of diabetes and obesity compared with the general population [12]. In the current study, $66 \%$ of our elderly patients had hypertension, which is similar to the prevalence of hypertension in the general elderly population (between $46 \%$ and $70 \%$ ) [17]. VWD patients with cardiovascular disease are often treated with anticoagulation or antiplatelet drugs, which could result in a more severe bleeding phenotype. The balance between the risk of bleeding and the risk of re-thrombosis should be carefully evaluated in VWD patients with cardiovascular events. Guidelines on the management of cardiovascular disease in VWD patients are lacking and further research on this subject is needed [40]. We also compared the comorbidities between the patients $<65$ years and the elderly based on their self-reported co-morbidities. As expected, co-morbidities were reported more frequently by elderly patients, especially for hypertension, diabetes, cancer, cardiovascular disease and depression.

The strength of our study is that we included a large number of elderly VWD patients and that our population covered almost all the patients with moderate or severe VWD in the Netherlands. Secondly, this is the first study on bleeding phenotype and VWF parameters in elderly VWD patients. However, the study also has some limitations. First, laboratory assays for VWF:Ag, VWF:RCo and FVIII:C have improved over time and there may be variability in the results of these assays. Next, the more measurements of VWF and FVIII were available for a single patient in the past 30 years, regression to the mean may have been observed. In addition, there may be some recall bias with regard to bleeding episodes and severity, because it is a cross-sectional study based on a selfadministered questionnaire. As we believe that recall bias was more likely to occur in older patients than in younger ones, and to be higher for less severe bleeding symptoms than for more severe bleedings, it might influence not only the rate of bleeding symptoms, but also the reported treatment and co-morbidity. To minimize recall bias, we verified the medical records of all elderly patients and analyzed separately data on bleeding symptoms in the year preceding inclusion in the study.

Another limitation is that the Tosetto Bleeding Questionnaire was used to calculate the lifetime prevalence of bleeding symptoms. This is a cumulative score, which indicates that the prevalence of bleeding symptoms potentially increases with each successive year of life. Patients might also have experienced a ceiling effect as they had already reached a maximum of the bleeding score early in life. We therefore probably observed a similar bleeding score for elderly and younger patients. In addition, patients born before 1964 may not have received high-quality clottingfactor concentrates in their first years of life, and may therefore have had severe bleedings that are included in the Tosetto Bleeding Score. We therefore also analyzed the bleeding symptoms occurring in the year preceding inclusion in the study, which is considered a better measurement for a patient's current bleeding phenotype.

In conclusion, VWF parameters and bleeding phenotype evolve with increasing age in VWD patients. VWF and FVIII levels increase with age in elderly type 1 patients with no amelioration in bleeding phenotype. In type 2 patients VWF and FVIII levels do not increase with age within the elderly population and in these patients aging is accompanied by increased bleeding. 


\section{Addendum}

F.W.G. Leebeek designed research, analyzed and interpreted data, and wrote the manuscript. Y.V. Sanders and M.A. Giezenaar performed research, analyzed and interpreted data, and wrote the manuscript. J. Eikenboom, J.G. van der Bom, M.H. Cnossen, K. Fijnvandraat, B.A.P. Laros-van Gorkom, K. Meijer and E.P. MauserBunschoten designed research, interpreted data and critically reviewed the manuscript. M.R. Nijziel and P.F. Ypma critically reviewed the manuscript. All authors gave their consent to the final version of the manuscript.

\section{Acknowledgements}

The authors would like to thank all participating patients. We also thank EM de Wee and all hemophilia nurses for their work in including patients and the Dutch Hemophilia Society for their help in performing the WiN study.

\section{Funding}

The WiN study was supported by research funding from the Dutch Hemophilia Foundation (Stichting Hemophilia) and CSL Behring (unrestricted grant).

\section{Disclosure of Conflict of Interests}

F.W.G. Leebeek received research support from CSL Behring for performing the WiN-study and has served on advisory boards of CSL Behring and Baxter in the past. Y.V. Sanders has been a teacher on educational activities of Baxter. J. Eikenboom received research support from CSL Behring and he has been a teacher on educational activities of Roche. E.P. Mauser-Bunschoten received research/educational support from CSL Behring, Bayer, Baxter, Novo Nordisk, Pfizer, Biovitrum and Sanquin. J.G. van der Bom has received unrestricted research/educational funding for various projects from the following companies: Bayer Schering Pharma, Baxter, CSL Behring, Novo Nordisk and Pfizer. In addition, she has been a consultant to Baxter and Pfizer, and she has been a teacher on educational activities of Bayer Schering Pharma. M.H. Cnossen has received unrestricted research/educational funding for various projects from the following companies: Bayer Schering Pharma, Baxter, Novo Nordisk, Pfizer and Novartis. K. Fijnvandraat is a member of the European Hemophilia Treatment and Standardisation Board sponsored by Baxter, has received unrestricted research grants from CSL Behring and Bayer, and has given lectures at educational symposiums organized by Pfizer, Bayer and Baxter. K. Meijer received research support from Bayer and Baxter and was a member of the Dutch hemophilia advisory board of CSL Behring. None of the other authors has a conflict of interest to declare.

\section{Supporting Information}

Additional Supporting Information may be found in the online version of this article:

Table S1. Classification of co-morbidities.

\section{Appendix}

\section{Study Group}

K. Fijnvandraat, S. Middeldorp: Academic Medical Center, Amsterdam. A. Kors, S. Zweegman: VU University Medical Center, Amsterdam. J. de Meris: Netherlands Hemophilia Society. M.H. Jonkers: Amphia Hospital, Breda. N. Dors: Catharina Hospital, Eindhoven. M.R. Nijziel: Maxima Medical Center, Eindhoven. K. Meijer, R.Y.J. Tamminga: University Medical Center Groningen, Groningen. P.W. van der Linden: Kennemer Gasthuis, Haarlem. P.F. Ypma: HagaZiekenhuis, The Hague. J.G. van der Bom, H.C.J. Eikenboom, F.J.W. Smiers: Leiden University Medical Center, Leiden. B. Granzen, K. Hamulyák: Maastricht University Medical Center, Maastricht. P. Brons, B.A.P. Laros-van Gorkom: Radboud University Medical Center, Nijmegen. F.W.G. Leebeek (principal investigator), M.H. Cnossen, Y.V. Sanders: Erasmus University Medical Center, Rotterdam. E.P. Mauser-Bunschoten (chairman steering committee): Van Creveldkliniek, University Medical Center, Utrecht.

\section{References}

1 James PD, Lillicrap D. von Willebrand disease: clinical and laboratory lessons learned from the large von Willebrand disease studies. Am J Hematol 2012; 87(Suppl. 1): S4-11.

2 Ruggeri ZM. Structure of von Willebrand factor and its function in platelet adhesion and thrombus formation. Best Pract Res Clin Haematol 2001; 14: 257-79.

3 De Wee EM, Sanders YV, Mauser-Bunschoten EP, van der Bom JG, Degenaar-Dujardin ME, Eikenboom J, De Goede-Bolder A, Laros-van Gorkom BA, Meijer K, Hamulyak K, Nijziel MR, Fijnvandraat K, Leebeek FW, for the WiN study group. Determinants of bleeding phenotype in adult patients with moderate or severe von Willebrand disease. Thromb Haemost 2012; 108: 68392.

4 Tosetto A, Rodeghiero F, Castaman G, Goodeve A, Federici AB, Batlle J, Meyer D, Fressinaud E, Mazurier C, Goudemand J, Eikenboom J, Schneppenheim R, Budde U, Ingerslev J, Vorlova Z, Habart D, Holmberg L, Lethagen S, Pasi J, Hill F, et al. A quantitative analysis of bleeding symptoms in type 1 von Willebrand disease: results from a multicenter European study (MCMDM-1 VWD). J Thromb Haemost 2006; 4: 766-73.

5 Sadler JE, Mannucci PM, Berntorp E, Bochkov N, Boulyjenkov V, Ginsburg D, Meyer D, Peake I, Rodeghiero F, Srivastava A. Impact, diagnosis and treatment of von Willebrand disease. Thromb Haemost 2000; 84: 160-74.

6 Sadler JE, Budde U, Eikenboom JC, Favaloro EJ, Hill FG, Holmberg L, Ingerslev J, Lee CA, Lillicrap D, Mannucci PM, Mazurier C, Meyer D, Nichols WL, Nishino M, Peake IR, Rodeghiero F, Schneppenheim R, Ruggeri ZM, Srivastava A, Montgomery RR, et al. Update on the pathophysiology and classification of von 
Willebrand disease: a report of the Subcommittee on von Willebrand Factor. $J$ Thromb Haemost 2006; 4: 2103-14.

7 Miesbach W, Berntorp E. When von Willebrand disease comes into age - a matter of change? Eur J Haematol 2011; 86: 496-501.

8 Vischer UM, Herrmann FR, Peyrard T, Nzietchueng R, Benetos A. Plasma von Willebrand factor and arterial aging. J Thromb Haemost 2005; 3: 794-5.

9 Mari D, Coppola R, Provenzano R. Hemostasis factors and aging. Exp Gerontol 2008; 43: 66-73.

10 van Loon JE, Kavousi M, Leebeek FW, Felix JF, Hofman A, Witteman JC, de Maat MP. von willebrand factor plasma levels, genetic variations, and coronary heart disease in an older population. J Thromb Haemost 2012; 10: 1262-9.

11 Mauser-Bunschoten EP, Fransen Van De Putte DE, Schutgens RE. Co-morbidity in the ageing haemophilia patient: the down side of increased life expectancy. Haemophilia 2009; 15: 853-63.

12 Sanders YV, Eikenboom J, de Wee EM, van der Bom JG, Cnossen MH, Degenaar-Dujardin ME, Fijnvandraat K, Kamphuisen PW, van Gorkom BA, Meijer K, Mauser-Bunschoten EP, Leebeek FW, for the WiN study group. Reduced prevalence of arterial thrombosis in von Willebrand disease. $J$ Thromb Haemost 2013; 11: 845-54.

13 de Wee EM, Leebeek FW, Eikenboom JC. Diagnosis and management of von Willebrand disease in The Netherlands. Semin Thromb Hemost 2011; 37: 480-7.

14 de Wee EM, Mauser-Bunschoten EP, van der Bom JG, DegenaarDujardin ME, Eikenboom HCJ, Fijnvandraat K, de GoedeBolder A, Laros-van Gorkom BAP, Meijer K, Raat H, Leebeek FWG, for the WiN study group. Health-related quality of life among adult patients with moderate and severe von Willebrand disease. J Thromb Haemost 2010; 8: 1492-9.

15 De Wee EM, Knol HM, Mauser-Bunschoten EP, van der Bom JG, Eikenboom JC, Fijnvandraat K, De Goede-Bolder A, Larosvan Gorkom B, Ypma PF, Zweegman S, Meijer K, Leebeek FW. Gynaecological and obstetric bleeding in moderate and severe von Willebrand disease. Thromb Haemost 2011; 106: 88592.

16 Boren MT, Ramey J. Thinking aloud: reconciling theory and practice. IEEE Trans Prof Commun 2000; 43: 261-78.

17 Kearney PM, Whelton M, Reynolds K, Muntner P, Whelton PK, He J. Global burden of hypertension: analysis of worldwide data. Lancet 2005; 365: 217-23.

18 Tosetto A, Castaman G, Rodeghiero F. Bleeding scores in inherited bleeding disorders: clinical or research tools? Haemophilia 2008; 14: 415-22.

19 World Health Organization. Definition of An Older or Elderly Person. Geneva, Switzerland: WHO, 2001.

20 Rodeghiero F, Tosetto A, Abshire T, Arnold DM, Coller B, James P, Neunert C, Lillicrap D, VWF ISj, Perinatal/Pediatric Hemostasis Subcommittees Working G. ISTH/SSC bleeding assessment tool: a standardized questionnaire and a proposal for a new bleeding score for inherited bleeding disorders. $J$ Thromb Haemost 2010; 8: 2063-5.

21 Conlan MG, Folsom AR, Finch A, Davis CE, Sorlie P, Marcucci $\mathrm{G}, \mathrm{Wu} \mathrm{KK}$. Associations of factor VIII and von Willebrand factor with age, race, sex, and risk factors for atherosclerosis. The Atherosclerosis Risk in Communities (ARIC) Study. Thromb Haemost 1993; 70: 380-5.

22 Rydz N, Grabell J, Lillicrap D, P J. Changes in von Willebrand factor level and von Willebrand activity with age in type 1 von Willebrand disease. Haemophilia 2012; 18: PO-MO-249.

23 Castaman G, Federici AB, Tosetto A, La Marca S, Stufano F, Mannucci PM, Rodeghiero F. Different bleeding risk in type 2A and $2 \mathrm{M}$ von Willebrand disease: a 2-year prospective study in 107 patients. $J$ Thromb Haemost 2012; 10: 632-8.

24 Sharma R, Gorbien MJ. Angiodysplasia and lower gastrointestinal tract bleeding in elderly patients. Arch Intern Med 1995; 155: 807-12.

25 Makris M. Gastrointestinal bleeding in von Willebrand disease. Thromb Res 2006; 118(Suppl. 1): S13-7.

26 Cooper BT, Weston CF, Neumann CS. Acute upper gastrointestinal haemorrhage in patients aged 80 years or more. $Q \mathrm{~J} \mathrm{Med}$ 1988; 68: 765-74.

27 Longstreth GF. Epidemiology of hospitalization for acute upper gastrointestinal hemorrhage: a population-based study. Am J Gastroenterol 1995; 90: 206-10.

28 Federici AB. Prophylaxis of bleeding episodes in patients with von Willebrand's disease. Blood Transfus 2008; 6(Suppl. 2): s26-32.

29 Abshire TC, Federici AB, Alvarez MT, Bowen J, Carcao MD, Cox GillJ, Key NS, Kouides PA, Kurnik K, Lail AE, Leebeek FW, Makris M, Mannucci PM, Winikoff R, Berntorp E, Vwd PN. Prophylaxis in severe forms of von Willebrand's disease: results from the von Willebrand Disease Prophylaxis Network (VWD PN). Haemophilia 2013; 19: 76-81.

30 Siboni SM, Mannucci PM, Gringeri A, Franchini M, Tagliaferri A, Ferretti M, Tradati FC, Santagostino E, von Mackensen S. Health status and quality of life of elderly persons with severe hemophilia born before the advent of modern replacement therapy. J Thromb Haemost 2009; 7: 780-6.

31 Franchini M, Mannucci PM. Co-morbidities and quality of life in elderly persons with haemophilia. Br J Haematol 2010; 148: 522-33.

32 Kistler U, Kramers-de Quervain I, Munzinger U, Kucher N. Bleeding complications after systematic switch of routine thromboprophylaxis for major orthopaedic surgery. Thromb Haemost 2008; 99: 1049-52.

33 Gommer AM, Poos MJJC. Prevalence, incidence and mortality according to age and gender. In: Volksgezondheid VTVNK, ed. Bilthoven: RIVM, 2010. http://www.nationaalkompas.nl. (Accessed 22 September 2011).

34 Fransen van de Putte DE, Fischer K, Pulles AE, Roosendaal G, Biesma DH, Schutgens RE, Mauser-Bunschoten EP. Non-fatal cardiovascular disease, malignancies, and other co-morbidity in adult haemophilia patients. Thromb Res 2012; 130: 157-62.

35 Mannucci PM, Schutgens RE, Santagostino E, Mauser-Bunschoten EP. How I treat age-related morbidities in elderly persons with hemophilia. Blood 2009; 114: 5256-63.

36 Fransen van de Putte DE, Makris M, Fischer K, Yee TT, Kirk L, Erpecum KJ, Patch D, Posthouwer D, Mauser-Bunschoten EP. Long-term follow-up of hepatitis $\mathrm{C}$ infection in a large cohort of patients with inherited bleeding disorders. $J$ Hepatol 2014; 60: 39-45.

37 Federici AB, Santagostino E, Rumi MG, Russo A, Mancuso ME, Soffredini R, Mannucci PM, Colombo M. The natural history of hepatitis $\mathrm{C}$ virus infection in Italian patients with von Willebrand's disease: a cohort study. Haematologica 2006; 91: 503-8.

38 Dutch Cancer Registry. the Netherlands: IKNL, 2014. http:// www.cijfersoverkanker.nl (Accessed 21 January 2014).

39 Franchini M, Lippi G, Montagnana M, Targher G, Zaffanello M, Salvagno GL, Rivolta GF, Perna CD, Tagliaferri A. Hemophilia and cancer: a new challenge for hemophilia centers. Cancer Treat Rev 2009; 35: 374-7.

40 Franchini M, Coppola A. Atherothrombosis in von Willebrand disease: an analysis of the literature and implications for clinical management. Semin Thromb Hemost 2012; 38: 185-99. 